\title{
Intervenção Cognitivo-Comportamental e Adesão ao Tratamento em Pessoas com HIV/Aids ${ }^{1}$
}

\author{
Quintino de Medeiros Faustino ${ }^{2}$ \\ Eliane Maria Fleury Seidl \\ Universidade de Brasília
}

\begin{abstract}
RESUMO - Foram investigados efeitos da intervenção cognitivo-comportamental sobre a adesão inadequada à terapia antirretroviral. Participaram dois homens (P1 e P2) acometidos pela Aids. Uma mulher soropositiva (P3) funcionou como controle. Foram comparadas avaliações de comportamento de adesão, estratégias de enfrentamento, expectativa de autoeficácia para aderir à terapia e variáveis biológicas de três momentos - linha de base (LB), imediatamente após (M2) e três meses depois (M3) da intervenção. Os participantes P1 e P2 relataram aumentos nos níveis de adesão à terapia, nos escores de autoeficácia e no enfrentamento focalizado no problema. A participante P3 manteve adesão insuficiente e baixos escores de autoeficácia. Conclui-se que a intervenção cognitivo-comportamental teve efeitos positivos sobre a adesão à terapia antirretroviral.
\end{abstract}

Palavras-chave: intervenção cognitivo-comportamental; HIV/Aids; adesão ao tratamento antirretroviral; enfrentamento; autoeficácia.

\section{Cognitive-Behavioral Intervention and Adherence to the Treatment by Persons with HIV/AIDS}

\begin{abstract}
The study investigated the effects of cognitive-behavioral intervention on inadequate adherence to the antiretroviral therapy. The participants were two men with AIDS (P1 and P2). A HIV positive woman (P3) was a control subject. It was compared behavior adherence evaluation, strategies of coping, expectation of self-efficacy and biological variables of three periods - baseline (BL), immediately after (M2) and three months after (M3) the intervention. The participants P1 and P2 reported increases on the levels of adherence to the therapy, on the scores of self-efficacy and on problem-focused coping. The participant P3 maintained unsatisfactory levels of adherence and low scores of self-efficacy. It was concluded that cognitivebehavioral intervention has positive effects on the adherence to the antiretroviral therapy.
\end{abstract}

Keywords: cognitive-behavioral intervention; HIV/AIDS; antiretroviral treatment adherence; coping; self-efficacy.

$\mathrm{O}$ advento da terapia antirretroviral (TARV) permitiu uma diminuição considerável nas manifestações clínicas associadas à infecção pelo vírus da imunodeficiência humana (HIV), ao lado de um ganho visível na qualidade de vida e no prognóstico das pessoas em tratamento. Seu principal objetivo é retardar o surgimento do quadro de imunodeficiência e melhorar a capacidade imunológica da pessoa infectada (Ministério da Saúde, 2007). A TARV se caracteriza por esquemas terapêuticos complexos. Para que as pessoas sob tratamento possam lidar com tais exigências, é imperativo o desenvolvimento de determinadas habilidades comportamentais e cognitivas (Kelly \& Kalichman, 2002).

Estudos apontam a resistência viral, a toxicidade dos medicamentos e a necessidade de níveis elevados de adesão como as principais barreiras ao sucesso prolongado da TARV (Ministério da Saúde, 2007). Além disso, para que a TARV seja eficaz, os estudos indicam a necessidade de uso dos medicamentos em níveis equivalentes ou superiores a $95 \%$

1 Artigo derivado da dissertação de mestrado do primeiro autor apresentada ao Instituto de Psicologia, da Universidade de Brasília, sob orientação da segunda autora.

2 Endereço para correspondência. Condomínio Jardim Botânico V, Conjunto "H", Casa 34, Jardim Botânico. Brasília, DF. CEP 71.680368. Fone: (61) 8136-9578, (61) 3208-3878.E-mail: quintino@unb. br/quintinomedeiros@yahoo.com.br. das doses recomendadas, o que torna o tratamento ainda mais desafiador, especialmente frente aos relatos na literatura de que 30 a $50 \%$ dos pacientes não conseguem manter tais níveis de adesão (Aspeling \& van Wyk, 2008; Molassiotis, Morris $\&$ Trueman, 2007; Russel \& cols., 2003).

A adesão ao tratamento, como outros comportamentos de saúde, tem sido estudada por vários modelos teóricos da psicologia. Dentre esses modelos, a abordagem cognitivo-comportamental tem destacado a relação entre variáveis psicológicas - percepção de controle, otimismo, autoeficácia, habilidades de enfrentamento do estresse, crenças de saúde e atitudes relacionadas à doença e ao tratamento - e comportamentos de adesão (Barros, 2003; Gebo, Keruly \& Moore, 2003; Sun, Zhang \& Fu, 2007; Tuldrà \& Wu, 2002).

O caráter educativo da abordagem cognitivo-comportamental tem se mostrado particularmente útil, favorecendo o desenvolvimento de habilidades, por parte de pessoas portadoras de doenças crônicas, para lidar de maneira eficaz com sua condição ao longo do tempo. Para tanto, o modelo propõe as seguintes estratégias para melhorar a capacidade de realização das escolhas e maior autocontrole sobre a condição de saúde: o desenvolvimento de habilidades relacionais, a administração do estilo de vida, a redução do estresse e o fortalecimento de habilidades para resolução de problemas, 
como estratégias para melhorar a capacidade de realização das escolhas e maior autocontrole sobre a condição de saúde (Cade, 2001; Wessler, 1996/1999).

White e Freeman (2000/2003) assinalam que o trabalho em grupo de base cognitivo-comportamental permite o desenvolvimento de tais habilidades. Entre as técnicas mais utilizadas para o alcance desse objetivo podemos citar a contestação de pensamentos e o balanço de vantagens e desvantagens (Feilstrecker, Hatzenberger \& Caminha, 2003), o autorregistro e monitoramento (Rehm, 1996/1999) e o relaxamento (Feilstrecker \& cols., 2003; Lipp, 1997).

Uma proposta de intervenção com enfoque cognitivocomportamental em grupo para melhorar a adesão ao tratamento em pessoas soropositivas foi avaliada por Murphy, Lu, Martin, Hoffman e Marelich (2002). Os inscritos foram distribuídos randomicamente no grupo controle $(n=25)$ e no grupo de intervenção $(n=27)$. Em ambos, os participantes realizaram avaliação inicial (linha de base) e duas avaliações de seguimento, uma logo após o encerramento da intervenção e outra, três meses depois. Ao final do estudo observou-se que o grupo experimental apresentou níveis maiores de adesão ao tratamento.

Outros estudos têm demonstrado que o senso de controle e a expectativa de autoeficácia estão relacionados à busca de soluções para problemas de saúde, incluindo a procura por informações relevantes e adesão às prescrições do tratamento (Haidt \& Rodin, 1999). Entre as teorias que têm apresentado um modelo explicativo para as relações entre comportamento e controle, podemos destacar a teoria da cognição social de Bandura (Haidt \& Rodin, 1999).

Seguindo tal concepção, é fundamental que o profissional da área de saúde entenda como as pessoas desenvolvem habilidades e percepções para lidar com as demandas do ambiente que afetam sua qualidade de vida ou levam ao adoecimento (Silva, 2004). Nessa perspectiva, Bandura (1994a) definiu autoeficácia como "as crenças das pessoas sobre suas capacidades para produzir determinados níveis de desempenho que exerçam influência sobre eventos que afetam suas vidas" ( $p$. 2). Estudos têm apontado que percepções mais otimistas de autoeficácia tendem a propiciar a capacidade de realização e o bem-estar psicológico das pessoas (Bandura 1994b).

Utilizando o referencial da teoria social cognitiva, Reynolds e cols. (2004) realizaram um estudo com 980 pessoas soropositivas que estavam iniciando o tratamento. O objetivo era avaliar crenças sobre a TARV e características psicossociais que poderiam influenciar a conduta de adesão. Os resultados indicaram que fatores pessoais e situacionais - como depressão, presença de estressores e menos escolaridade - estiveram relacionados a níveis mais reduzidos de confiança na efetividade da TARV e na autoeficácia percebida para aderir ao tratamento antirretroviral. Os resultados indicaram a importância de identificar, de modo oportuno, as variáveis pessoais e situacionais que podem interferir negativamente no comportamento de adesão de pessoas em TARV, para empreender ações que auxiliem o paciente no manejo das mesmas.

Outra variável psicológica de destaque nesse campo de estudos da psicologia da saúde são estratégias de enfrentamento. Estudos têm apontado que as estratégias de enfrentamento mediam a relação entre eventos estressores e indicadores de capacidade de adaptação, como saúde física e aspectos psicológicos (Endler, Parker \& Summerfeldt, 1998; Folkman, Lazarus, Gruen \& DeLongis, 1986).

Há duas modalidades principais de estratégias de enfrentamento: enfrentamento focalizado no problema e enfrentamento focalizado na emoção. Estudos recentes têm apontado ainda para a ocorrência de outras modalidades de enfrentamento, como a busca de suporte social para a resolução da situação de estresse e busca de práticas religiosas (Antoniazzi \& cols., 1998; Seidl, Tróccoli \& Zannon, 2001). A avaliação das estratégias de enfrentamento no contexto da adesão ao tratamento em HIV/Aids decorre do fato de que aderir à medicação pode se constituir em uma modalidade de enfrentamento focada no problema. Assim, pessoas que apresentam estratégias de esquiva muitas vezes apresentam níveis insatisfatórios de adesão.

O objetivo do presente estudo foi avaliar os efeitos de intervenção cognitivo-comportamental sobre a conduta de adesão de pessoas vivendo com HIV/Aids com dificuldades para aderir ao tratamento antirretroviral. Foram comparados indicadores em três momentos: antes da intervenção (linha de base), imediatamente após (momento 2) e três meses depois do término da intervenção (momento 3). O comportamento de adesão foi avaliado juntamente com variáveis psicológicas (estratégias de enfrentamento e autoeficácia para uso de TARV) e biológicas (níveis de linfócitos T CD4 e de carga viral). Além disso, foi mensurado com base no percentual de perda (não ingestão) de comprimidos/cápsulas dos medicamentos antirretrovirais em relação ao número de comprimidos/cápsulas prescritos, na última semana (últimos sete dias) e/ou no último mês (últimos 30 dias), mediante autorrelato do participante.

\section{Método}

\section{Delineamento}

O estudo teve delineamento quase experimental, longitudinal de curto prazo, sendo comparados os resultados das variáveis selecionadas em três momentos: linha de base (LB), momento 2 (M2) e momento 3 (M3).

$\mathrm{Na}$ fase de recrutamento, pessoas soropositivas foram informadas sobre o trabalho em duas unidades de saúde especializadas e em um grupo de apoio a pessoas com HIV/ Aids do Distrito Federal, mediante afixação de cartazes, entrega de convites impressos e convite verbal. Seis pessoas aceitaram o convite. Após avaliação da linha de base, duas delas não foram indicadas para participar, pois uma apresentava transtornos psiquiátricos e a outra não apresentava dificuldades de adesão aos medicamentos antirretrovirais (ARV), mas ao tratamento para outra condição crônica que a acometia. Um outro participante aceitou e participou da avaliação da LB, porém não foi mais encontrado pela equipe, sendo excluído do estudo.

Uma outra participante (P3) fez a avaliação da LB, mas faltou aos atendimentos propostos, não se submetendo à intervenção. Como não compareceu aos atendimentos, mesmo após telefonemas da equipe estimulando sua participação, 
optou-se por convidá-la para participar no seguimento - três meses depois -, inserindo-se no estudo como sujeito controle. Assim, dois participantes foram submetidos à intervenção (P1 e P2) e uma participante (P3) não foi submetida à intervenção. Em suma, esse ajuste no delineamento ocorreu em função da não adesão de P3 à intervenção.

\section{Participantes}

Para participação no estudo foram considerados como critérios de inclusão: comportamento de adesão insatisfatório (não ingestão autorrelatada de mais que $6 \%$ do número de comprimidos/cápsulas prescritos, na última semana e/ou mês anterior) ou necessidade de intervenção psicossocial para prevenção de recaída tendo em vista a ocorrência de abandono do tratamento e histórico recente de problemas de adesão. Foram estabelecidos os seguintes critérios de exclusão: presença de transtornos psiquiátricos que dificultassem a expressão verbal, escolaridade inferior à terceira série do Ensino Fundamental e não atendimento do critério de adesão insatisfatória.

Abaixo, seguem informações sociodemográficas e médico-clínicas, dos três participantes incluídos no estudo:

- P1: 35 anos, sexo masculino, solteiro, ensino médio completo, residia em instituição de apoio (abrigo). Recebeu o diagnóstico em 1998, fazia uso dos ARV desde 2002, tendo trocado uma vez de esquema terapêutico. Tinha feito interrupção da TARV por conta própria uma vez. Apresentou nível razoável de conhecimento sobre Aids, mas tinha pouca informação sobre como se dava a ação dos antirretrovirais no organismo.

- P2: 29 anos, sexo masculino, casado, ensino fundamental incompleto e residência alugada. Estava fazendo uso dos ARV desde 2001, ano em que teve o diagnóstico da infecção pelo HIV. Havia trocado de esquema antirretroviral diversas vezes. Apresentou nível razoável de conhecimento sobre Aids e seu tratamento.

- P3: 36 anos, sexo feminino, solteira, morava só, ensino fundamental incompleto e residência alugada. Fazia uso dos ARV desde 1994, ano em que recebeu o diagnóstico. Estava utilizando o quinto esquema com ARV. Sua história de tratamento se caracterizava pela não adesão. Apresentou um nível razoável de conhecimento sobre aids e seu tratamento.

\section{Instrumentos}

Os instrumentos foram escolhidos com o objetivo de avaliar e mensurar as variáveis do estudo e o comportamento de adesão dos participantes na LB e nos momentos 2 e 3.

Roteiro de entrevista de linha de base - aspectos sociodemográficos e médico-clínicos. Elaborado em estudo sobre adesão à TARV (Seidl, Melchíades, Farias \& Brito, 2007), contendo questões fechadas e abertas sobre situação conjugal, última série cursada, situação empregatícia, renda familiar, tempo de diagnóstico, esquema terapêutico, condição clínica autorrelatada em relação à soropositividade, tempo de uso da TARV, interrupção atual e/ou anterior da TARV por conta própria, percepção sobre condições atuais de saúde e benefícios da TARV e conhecimento sobre HIV/Aids e TARV.

Resultados médico-clínicos. Os dados sobre os níveis de linfócitos T CD4 e da carga-viral plasmática foram obtidos dos prontuários dos participantes.

Escala de Expectativa de Autoeficácia para Seguir Prescrição Antirretroviral. Instrumento brasileiro construído e validado por Leite, Drachler, Centeno, Pinheiro e Amato (2002) e utilizado para a avaliação de autoeficácia para realização do tratamento com ARV. Escala unifatorial, composta de 21 itens e as respostas dadas em escala Likert de 5 pontos, variando de 0 (com certeza não vou tomar) a 4 (vou tomar com certeza). Demonstrou, nos testes psicométricos, validade de construto e indicador de consistência interna (alpha de Cronbach $=0,96$ ) adequados para medir autoeficácia para tratamento antiretroviral. Ao final, foi incluída questão aberta sobre outras situações que poderiam afetar o uso da TARV.

Escala Modos de Enfrentamento de Problemas - EMEP. Escala validada por Seidl e cols., (2001) para a população brasileira. A escala autoaplicável avaliou as estratégias de enfrentamento cognitivas e/ou comportamentais que a pessoa utilizava para lidar com estressores específicos relacionados à situação de soropositividade e que sobrecarregavam seus recursos pessoais. Escala composta de 45 itens, distribuídos em quatro fatores: enfrentamento focalizado no problema (alpha de Cronbach $=0,84 ; 18$ itens); enfrentamento focalizado na emoção (alpha de Cronbach $=0,81 ; 15$ itens); busca de práticas religiosas/pensamento fantasioso (alpha de Cronbach $=0,74 ; 7$ itens); busca de suporte social (alpha de Cronbach $=0,70 ; 5$ itens). Os escores da EMEP, obtidos mediante média aritmética, variavam de 1 a 5 , sendo que escores mais elevados indicavam maior utilização de determinada estratégia de enfrentamento. As respostas foram dadas em escala de Likert de 5 pontos $(1=$ nunca faço isso; $5=$ faço isso sempre). Ao final do instrumento foi incluída questão aberta, cuja resposta era opcional, indagando: "Você tem feito alguma outra coisa para lidar ou enfrentar esta situação?".

Roteiros de entrevista e instrumentos dos momentos 2 e 3. Na aplicação após a intervenção foi utilizada uma versão modificada do roteiro de entrevista de linha de base, com alguns itens suprimidos e o acréscimo de perguntas sobre se o trabalho havia atendido às necessidades e expectativas iniciais do participante, o que deveria ser mantido no trabalho a ser realizado em intervenções futuras, bem como o que deveria ser mudado ou acrescentado. Três meses após o término da intervenção, o roteiro utilizado foi semelhante ao anterior sendo que foram acrescentados itens para avaliar o comportamento de adesão na última semana e no último mês. As duas escalas citadas foram reaplicadas em M2 e em M3.

\section{Coleta de dados}

O projeto de pesquisa foi aprovado pelo Comitê de Ética em Pesquisa da Faculdade de Ciências da Saúde da Universidade de Brasília (Projeto CEP/FS/UnB 066/2005). Os pacientes que consentiram em participar e assinaram o Termo de Consentimento Livre e Esclarecido foram incluídos. 
Tabela 1. Descrição das técnicas cognitivo-comportamentais empregadas nos encontros.

\begin{tabular}{ll}
\hline \multicolumn{1}{c}{ Técnica } & \multicolumn{1}{c}{ Descrição } \\
\hline & $\begin{array}{l}\text { Técnica direcionada à modificação de crenças irracionais e de concepções fatalistas } \\
\text { e catastróficas sobre a enfermidade e o tratamento. Objetivava o desenvolvimento } \\
\text { de avaliações mais realísticas das situações relativas à doença e ao tratamento. }\end{array}$ \\
$\begin{array}{ll}\text { Reestruturação cognitiva (Feilstrecker \& } \\
\text { cols., 1996/2003; Caballo \& Buela-Casal, }\end{array}$ & $\begin{array}{l}\text { Pautou-se em orientações para que o participante se inquirisse acerca da validade e } \\
\text { veracidade de seus pensamentos com base nas evidências que possuía, na existên- } \\
\text { cia de outras possibilidades de interpretação para o evento e nas possibilidades de } \\
\text { alteração ou eliminação de pensamentos disfuncionais sobre a enfermidade e o } \\
\text { tratamento. }\end{array}$ \\
\hline
\end{tabular}

Incentivo para que os participantes pensassem sobre as vantagens e desvantagens de aderir e de não aderir à TARV, fornecendo subsídios para a identificação de

Balanço de vantagens e desvantagens (Feilstrecker \& cols., 1996/2003) crenças sobre a medicação e de contingências favorecedoras ou não da conduta de adesão. A técnica é útil para processos de tomada de decisão, permitindo que a pessoa deixe de se comportar exclusivamente com base em padrões de pensamentos dicotômicos, relacionando as vantagens e desvantagens de uma determinada situação.

\begin{tabular}{ll}
\hline $\begin{array}{l}\text { Autorregistro e monitoramento } \\
\text { (Rehm, 1996/1999) }\end{array}$ & $\begin{array}{l}\text { Consistiu em levar o participante a observar e registrar sistematicamente seu próprio } \\
\text { comportamento de uso da medicação ARV em determinado período de tempo } \\
\text { (semana). O autorregistro pode ser utilizado para avaliar o comportamento, seus } \\
\text { antecedentes, suas consequências, as emoções vivenciadas ou as relações entre essas } \\
\text { variáveis. }\end{array}$ \\
\hline $\begin{array}{l}\text { Relaxamento diafragmático } \\
\text { (Vera \& Villa, 19961999; Lipp, 1997) }\end{array}$ & $\begin{array}{l}\text { Por meio do controle da respiração, os pacientes são levados a estados de relaxamen- } \\
\text { to. Escolhida por sua praticidade, facilidade de execução e de aprendizagem. }\end{array}$ \\
\hline $\begin{array}{l}\text { Solução de problemas (Nezu \& Nezu, } \\
\text { 1996/1999) }\end{array}$ & $\begin{array}{l}\text { Refere-se à busca de soluções eficazes para uma situação-problema, como a dificul- } \\
\text { dade de adesão satisfatória ao tratamento. Envolve etapas como a definição do pro- } \\
\text { blema, levantamento de alternativas, tomada de decisão, prática da solução proposta } \\
\text { e verificação. }\end{array}$ \\
\hline $\begin{array}{l}\text { Disponibilização de informação sobre HIV/ } \\
\text { aids e TARV }\end{array}$ & $\begin{array}{l}\text { Foram oferecidas informações referentes à HIV/Aids, CD4, carga viral e TARV, vi- } \\
\text { sando a melhoria do nível de informação e a modificação de mitos e de pensamentos } \\
\text { disfuncionais sobre esses temas. Foram usados materiais gráficos e vídeos educativos } \\
\text { com esse objetivo. }\end{array}$ \\
\hline
\end{tabular}

Os participantes P1 e P2 foram avaliados individualmente em três momentos distintos: na linha de base (LB), imediatamente após o término da intervenção em grupo (M2) e três meses depois do término da intervenção (M3). No caso de P3, não houve avaliação em M2 pois não participou da intervenção. A informação sobre a variável adesão ao tratamento foi obtida por autorrelato referente ao esquema atual da TARV (nomes dos medicamentos, quantidade diária de cada medicamento e horários). Era solicitado, então, que o participante estimasse quantos comprimidos/cápsulas dos ARV teria deixado de tomar na semana e no mês anteriores, o que permitiu o cálculo do percentual de comprimidos não ingeridos na última semana e no último mês. Esse percentual foi computado a partir do número total de comprimidos/ cápsulas que deveria ser tomado. Relatos sobre atrasos nos horários de uso da medicação foram obtidos, mas não foram utilizados na análise de dados. A informação sobre a prescrição dos ARV foi confirmada pelo pesquisador mediante consulta aos registros médicos nos prontuários dos pacientes.

\section{Intervenção}

Após a avaliação de linha de base, os participantes foram convidados a iniciar a intervenção. O procedimento havia sido planejado para ocorrer em grupo, mas de fato ocorreu em dupla, considerando que apenas duas pessoas aderiram à atividade. A intervenção foi baseada em referencial teórico-metodológico cognitivo-comportamental (Campos \& Thomason, 1998), com a utilização de técnicas específicas (Tabela 1) e pautada em fundamentos de grupo psicoeducativo (Ministério da Saúde, 2008). O grupo foi conduzido por dois facilitadores, psicólogos experientes no trabalho com pessoas soropositivas.

Foram realizados cinco encontros semanais, com cerca de duas horas de duração cada. Os encontros tinham o objetivo de integrar os participantes, manter um vínculo entre eles e os facilitadores, identificar e manejar dificuldades em relação ao uso da TARV, melhorar o nível de conhecimento sobre HIV/Aids e TARV, aumentar a percepção de benefícios sobre o tratamento, modificar crenças catastróficas sobre 
Tabela 2. Descrição da sequência de atividades e técnicas principais aplicadas na intervenção.

\begin{tabular}{|c|c|}
\hline Sessão & Atividades \\
\hline $1^{\mathrm{a}}$ & $\begin{array}{l}\text { - Apresentação dos participantes e dos facilitadores, descrição dos objetivos do trabalho, estabelecimento de contrato e do } \\
\text { compromisso de melhorar a adesão à TARV } \\
\text { - Preenchimento da matriz de vantagens e desvantagens da adesão à TARV } \\
\text { - Preenchimento de tabela de horários e doses do esquema terapêutico de cada participante. } \\
\text { - Apresentação e instrução sobre o preenchimento da ficha de automonitoramento } \\
\text { - Entrega do material de apoio e da ficha de automonitoramento (tarefa de casa) } \\
\text { - Avaliação do encontro }\end{array}$ \\
\hline $2^{\mathrm{a}}$ & $\begin{array}{l}\text { - Relato sobre o uso da TARV na semana a partir do registro da ficha de automonitoramento e discussão das estratégias de } \\
\text { enfrentamento para as dificuldades evidenciadas } \\
\text { - Discussão da perspectiva de futuro: ênfase na importância da mudança e nos comportamentos que favorecem e que difi- } \\
\text { cultam a adesão } \\
\text { - Levantamento do conhecimento dos participantes sobre HIV/Aids e TARV } \\
\text { - Apresentação do vídeo "Adesão". Reflexão participativa sobre o conteúdo do vídeo, a infecção pelo HIV, a ação dos ARV } \\
\text { e a importância do seguimento das prescrições } \\
\text { - Instrução e prática dos participantes em relaxamento diafragmático } \\
\text { - Entrega da ficha de automonitoramento da semana e material educativo (tarefa de casa) }\end{array}$ \\
\hline $3^{\mathrm{a}}$ & $\begin{array}{l}\text { - Relato sobre o uso da TARV na semana, análise e discussão da ficha de automonitoramento } \\
\text { - Reforço das mudanças apresentadas e elaboração de estratégias de enfrentamento } \\
\text { - Discussão de dúvidas sobre HIV/Aids, TARV, CD4 e carga viral } \\
\text { - Levantamento e reforço da importância de suporte social, emocional e instrumental } \\
\text { - Levantamento das perspectivas de futuro e das estratégias utilizadas para alcançá-las } \\
\text { - Entrega da ficha de automonitoramento e das tarefas de casa }\end{array}$ \\
\hline $4^{\mathrm{a}}$ & $\begin{array}{l}\text { - Análise e discussão da ficha de auto-monitoramento } \\
\text { - Discussão da eficácia da TARV e dos efeitos negativos da interrupção do tratamento } \\
\text { - Discussão sobre estratégias para lidar com dificultadores para o uso dos ARV em situações de maior vulnerabilidade } \\
\text { - Reforço do compromisso inicial de seguimento do tratamento, com ênfase na motivação e nas mudanças positivas apre- } \\
\text { sentadas pelos participantes } \\
\text { - Reforço da importância de manter a adesão e da proteção oferecida pelos ARV. } \\
\text { - Entrega da ficha de automonitoramento e das tarefas de casa }\end{array}$ \\
\hline $5^{\mathrm{a}}$ & $\begin{array}{l}\text { - Análise e discussão da ficha de automonitoramento } \\
\text { - Avaliação das dificuldades para aderir à TARV e discussão de estratégias de enfrentamento para tais dificuldades } \\
\text { - Avaliação das mudanças percebidas pelos participantes ao longo do trabalho } \\
\text { - Reforço das percepções e das mudanças comportamentais positivas apresentadas } \\
\text { - Levantamento dos planos de futuro e discussão de sua importância para o desenvolvimento pessoal } \\
\text { - Avaliação do trabalho realizado, levantamento de críticas e sugestões para a elaboração de iniciativas de intervenção futuras }\end{array}$ \\
\hline
\end{tabular}

HIV/Aids e TARV, melhorar a expectativa de autoeficácia para seguimento das prescrições antirretrovirais e favorecer o emprego de estratégias de enfrentamento adaptativas. As sessões foram gravadas, com consentimento dos participantes, e seu conteúdo foi transcrito para análise de dados.

Foram utilizadas diversas técnicas, como registro e automonitoramento (facilitadora do autoconhecimento sobre a própria conduta de adesão), balanço de vantagens e desvantagens da adesão, resolução de problemas, relaxamento, além de dinâmicas de grupo para integração dos participantes (Tabela 1).

A sequência de atividades adotada na intervenção está apresentada na Tabela 2 .

Apesar da aceitação para participar do estudo na LB, P3 não compareceu à intervenção em grupo, mesmo após contatos telefônicos que reiteraram o convite, informando as datas, horários e local dos encontros. No entanto, aceitou o convite para participar da entrevista no Momento 3, passando a figurar como caso-controle.

\section{Análise de dados}

Para análise quantitativa de dados foi utilizado o software Statistical Package for Social Sciences (SPSS) 11.5. Para comparar os resultados dos participantes nos três momentos e identificar se houve diferença significativa nos escores das medidas de autoeficácia e enfrentamento, foi utilizado o teste $t$ de Student para dados pareados, ou sua versão não paramétrica (teste $T$ de Wilcoxon), quando houve quebra dos pressupostos de normalidade, como na variável autoeficácia (Dancey \& Reidy, 2006). Foram comparados, ainda, os percentuais relativos à perda de doses dos participantes nos vários momentos do estudo. Também foram analisados os resultados dos níveis de células T CD4 e os resultados dos testes de carga viral.

Outros aspectos referentes a crenças e percepções sobre o tratamento foram descritos, nos diferentes momentos investigados. O conteúdo dos relatos verbais das entrevistas foi transcrito e analisado. 
Tabela 3. Comprimidos/cápsulas $(\mathrm{C} / \mathrm{C})$ prescritos, não ingeridos na última semana e no último mês, na linha de base, nos momentos 2 e 3 , segundo autorrelato dos participantes.

\begin{tabular}{|c|c|c|c|c|c|c|c|}
\hline \multirow[t]{2}{*}{ Participantes } & \multirow[t]{2}{*}{$\begin{array}{c}\text { C/C prescritos } \\
\text { por semana/mês }\end{array}$} & \multicolumn{2}{|c|}{$\begin{array}{c}\text { Linha de base } \\
\text { C/C não ingeridos na } \\
\text { semana/mês anterior }\end{array}$} & \multicolumn{2}{|c|}{$\begin{array}{c}\text { Momento } 2 \\
\text { C/C não ingeridos na } \\
\text { semana/mês anterior }\end{array}$} & \multicolumn{2}{|c|}{$\begin{array}{c}\text { Momento } 3 \\
\text { C/C não ingeridos na } \\
\text { semana/mês anterior }\end{array}$} \\
\hline & & $\mathrm{n}$ & $\%$ & $\mathrm{n}$ & $\%$ & $\mathrm{n}$ & $\%$ \\
\hline P1 & $35 / 150$ & $5 / 25$ & $14,3 / 16,7$ & $0 / 0$ & $0 / 0$ & $0 / 4$ & $0 / 3$ \\
\hline $\mathrm{P} 2$ & $42 / 180$ & $4 / 15$ & $9,5 / 8,3$ & $0 / 0$ & $0 / 0$ & $0 / 6$ & $0 / 3,3$ \\
\hline P3 & $56 / 240$ & $56 / 120$ & $100 / 50$ & -- & -- & $56 / 224$ & $100 / 100$ \\
\hline
\end{tabular}

\section{Resultados}

\section{TARV e conduta de adesão}

Os três participantes atendiam à condição para participação do estudo, pois na linha de base apresentavam níveis de adesão inferiores a $95 \%$ das doses prescritas, conforme apresentado na Tabela 3.

Observou-se que no M2, os relatos de P1 e P2 foram de que nenhum comprimido tinha sido perdido na última semana e no último mês. No M3, P1 e P2 apresentaram aproximadamente $3 \%$ de perdas de doses no mês anterior à entrevista, e adesão plena $(100 \%$ das doses prescritas tomadas) na semana anterior, indicando a manutenção de níveis de adesão dentro do limite esperado pelo estudo. O participante $\mathrm{P} 3$, por sua vez, apresentou níveis elevados de não adesão na LB e em M3.

\section{Ocorrência de efeitos colaterais e percepção sobre a proteção da TARV}

Os três participantes relataram estar sentindo algum efeito colateral nos diferentes momentos e, com exceção de P2 no M3, avaliavam os efeitos sentidos como desagradáveis. Somente P2 apresentou mudança da percepção de quão desconfortáveis eram os efeitos colaterais, apresentando no M3 um relato de que os efeitos não eram desconfortáveis.

Com relação à percepção de dificuldade quanto a realizar o tratamento, P1disse ser muito difícil realizar a TARV na LB, apresentando uma mudança positiva em M2 e M3, quando apontou não ser difícil realizar o tratamento. O participante P2 também alterou sua percepção acerca do nível de dificuldade para realização da TARV, reduzindo pensamentos catastróficos e a maximização de consequências negativas sobre o uso do medicamento. $\mathrm{Na} \mathrm{LB}$, ele relatou que era muito difícil fazer o tratamento, mudando seu relato no sentido de que era um pouco difícil. O participante P3, por outro lado, manteve a percepção sobre o nível de dificuldade para a realização da TARV, relatando ser muito difícil realizar o tratamento em ambas as entrevistas.

Com relação a quanto os ARV o protegeriam do agravamento da doença e do aparecimento de doenças oportunistas, P1 manteve um padrão positivo, avaliando que a medicação protegeria completamente (LB e M3) ou muito (M2). O participante $\mathrm{P} 2$ disse, na $\mathrm{LB}$, que os $\mathrm{ARV}$ protegeriam quase nada sua saúde, tendo respostas mais positivas nos momentos seguintes. O participante $\mathrm{P} 3$ não mudou sua resposta em M3, respondendo que os ARV protegeriam mais ou menos sua saúde. Ao serem perguntados sobre o quanto a boa saúde de uma pessoa HIV+ dependia do uso dos ARV, todos disseram, nas diferentes avaliações, que esta dependia muito ou completamente da TARV.

\section{Percepção sobre a situação de saúde e impedimento de atividades cotidianas}

Sobre a autoavaliação da condição de saúde, P3 avaliou sua saúde como regular em ambas as entrevistas, não havendo mudança nessa avaliação. O participante P2 avaliou inicialmente sua saúde como ruim, no M2 sua avaliação era de que estava com uma condição de saúde boa e no M3, que sua situação era regular. O participante $\mathrm{P} 1$ apresentou uma mudança na percepção de sua condição de saúde, passando de precária na LB, para boa no M2, chegando a muito boa no M3. Verifica-se, assim, a tendência de mudança positiva dessa avaliação apenas nos relatos dos dois participantes expostos à intervenção.

$\mathrm{Na} \mathrm{LB}$, todos os participantes relataram que nos meses imediatamente anteriores ao da entrevista tiveram problemas de saúde (adoecimentos e internações) que os impediram de realizar atividades cotidianas. Os participantes P1 e P2 não apresentaram em M2 e M3 relatos de situações similares que os tivessem impedido de realizar suas atividades rotineiras. O participante $\mathrm{P} 3$, por sua vez, disse que suas atividades rotineiras foram prejudicadas por problemas de saúde nos dois momentos investigados.

\section{Autoeficácia}

A Figura 1 apresenta os escores que os três participantes obtiveram na Escala de Expectativa de Autoeficácia para Seguir Prescrição Antirretroviral.

O participante $\mathrm{P} 1$ apresentou níveis satisfatórios de autoeficácia nos três momentos. No entanto, na LB, ele disse não saber se tomaria a medicação se estivesse bem de saúde, se tivesse níveis indetectáveis de carga viral e se houvesse mudança constante da equipe médica que o atendia. Já no M3, ele apresentou níveis máximos de autoeficácia em todos 


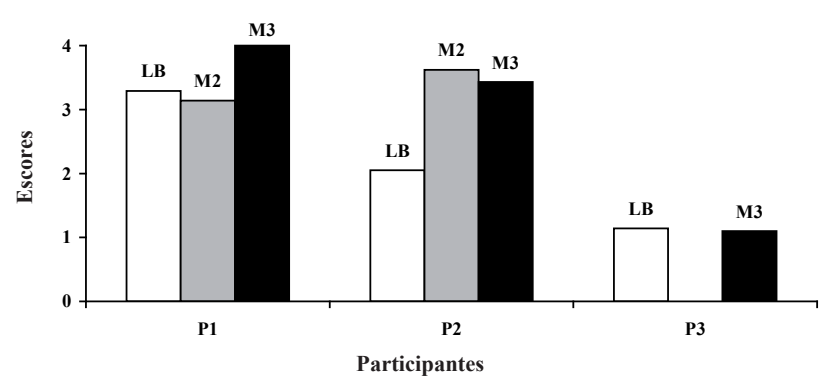

Figura 1. Escores dos participantes na Escala de Expectativa de Autoeficácia para seguir Prescrição Antirretroviral na Linha de Base (LB), no Momento 2 (M2) e no Momento 3 (M3).

os itens, referindo ter certeza quanto a ingerir a medicação em todas as situações apresentadas no instrumento. Os dados de P1 mostraram, na LB, que a melhora das condições de saúde poderia constituir risco para a interrupção ou uso inadequado da TARV.

$\mathrm{O}$ participante $\mathrm{P} 2$ relatou, na $\mathrm{LB}$, que não iria tomar a medicação nos casos de viagens ou passeios, se estivesse na rua, sentindo-se doente ou se os remédios lhe causassem efeitos ruins, além de outras quatro situações que ele achava que não tomaria e cinco que ele não sabia dizer se tomaria a medicação. No M2, o participante assinalou que não saberia se iria tomar caso estivesse na presença de alguém que ele não gostaria que soubesse que era portador do vírus ou no meio de pessoas estranhas, sendo que nas demais situações ele tomaria com certeza ou achava que iria tomar. Já em M3, P2 disse não saber se iria ingerir a medicação caso tivesse dificuldades para engolir os remédios e se tivessem causando efeito ruim, sendo que as demais situações foram assinaladas como ele tomando com certeza ou achando que iria tomar. Observou-se em P2 um leque muito variado de situações que poderiam implicar em adesão insatisfatória, indicando uma diversidade de contextos de risco.

O participante P3 apresentou níveis baixos de autoeficácia em ambas as avaliações, com a maioria dos itens assinalados como "não vou tomar mesmo" e "acho que não vou tomar". Esses resultados são indicadores da manutenção de uma diversidade de situações de risco para a adesão à TARV, sem modificação nos dois momentos avaliados.
Para comparar as médias de cada participante nos três momentos foi realizado o teste $t$ de Student pareado (ver Tabela 4). Era esperado que houvesse um aumento entre a LB e o M2 e estabilidade ou melhora entre M2 e M3, para P1 e P2. No caso de P3, como ela não participou dos atendimentos, era esperado que houvesse estabilidade nos seus escores, que foram baixos na LB.

Apesar de o escore de P1 ter sido menor no M2, quando comparado com a LB, essa diferença não foi significativa $(t=0,9 ; p=0,38)$. Comparando o M2 e o M3 e a LB e o $\mathrm{M} 3$, encontramos diferença estatística significativa entre os momentos avaliados. Para P2, encontramos diferenças significativas quando comparamos a LB com o M2 e com M3, com valores de $p$ menores que 0,001 . No caso de P3, não foi encontrada diferença significativa entre a LB e o M3, indicando que não houve mudança nos escores obtidos na medida de autoeficácia entre os dois momentos investigados.

\section{Estratégias de enfrentamento}

A Tabela 5 apresenta os escores de P1, P2 e P3 na EMEP nos três momentos e os valores do teste $t$ entre a LB e o M3.

O participante P1 apresentou predomínio de estratégias focadas na emoção, indícios prováveis de dificuldades de ajustamento à soropositividade, níveis baixos de focalização no problema e de busca de suporte social. Observou-se que P1 apresentou mudanças significativas nos escores obtidos nas três modalidades de estratégias de enfrentamento. Exceção pode ser apontada em pensamento fantasioso/busca de práticas religiosas que, apesar de ter obtido escores gradativamente maiores, não teve incremento significativo.

$\mathrm{O}$ participante $\mathrm{P} 2$, mesmo tendo apresentado níveis satisfatórios do emprego de estratégias com foco no problema na LB, ainda relatou aumento significativo em seu uso nos dois momentos subsequentes. De uma maneira geral, não foi encontrada mudança significativa nas estratégias focalizadas na emoção e em busca de suporte social, com níveis estáveis nos momentos seguintes, sendo que pensamento fantasioso/ busca por práticas religiosas permaneceu estável. Podemos perceber que $\mathrm{P} 3$ apresentou mudanças significativas em quase todas as estratégias entre a LB e o M3. Entretanto, percebe-se

Tabela 4. Amostras pareadas, diferença das médias, valores do teste $t$ de Wilcoxon e nível de significância na Escala de Autoeficácia.

\begin{tabular}{|c|c|c|c|c|c|}
\hline Participante & Pares & $\begin{array}{c}\text { Diferença } \\
\text { das médias }\end{array}$ & Desvio-padrão & $\mathrm{t}$ & $\mathrm{p}$ \\
\hline \multirow{3}{*}{$\mathbf{P 1}$} & LB - M2 & 0,143 & 0,727 & 0,90 & 0,366 \\
\hline & $\mathrm{M} 2-\mathrm{M} 3$ & 0,857 & 0,358 & 4,24 & $\leq 0,001$ \\
\hline & $\mathrm{LB}-\mathrm{M} 3$ & 0,714 & 0,717 & 3,22 & $\leq 0,001$ \\
\hline \multirow{3}{*}{$\mathbf{P 2}$} & $\mathrm{LB}-\mathrm{M} 2$ & 1,571 & 1,535 & 3,23 & $\leq 0,001$ \\
\hline & $\mathrm{M} 2-\mathrm{M} 3$ & 0,190 & 0,749 & 1,15 & 0,248 \\
\hline & $\mathrm{LB}-\mathrm{M} 3$ & 1,381 & 1,203 & 3,45 & $\leq 0,001$ \\
\hline P3 & LB - M3 & 0,047 & 1,910 & 0,11 & 0,915 \\
\hline
\end{tabular}


Tabela 5. Médias de P1, P2 e P3 na EMEP e valores da comparação entre LB e M3 (três meses após a intervenção).

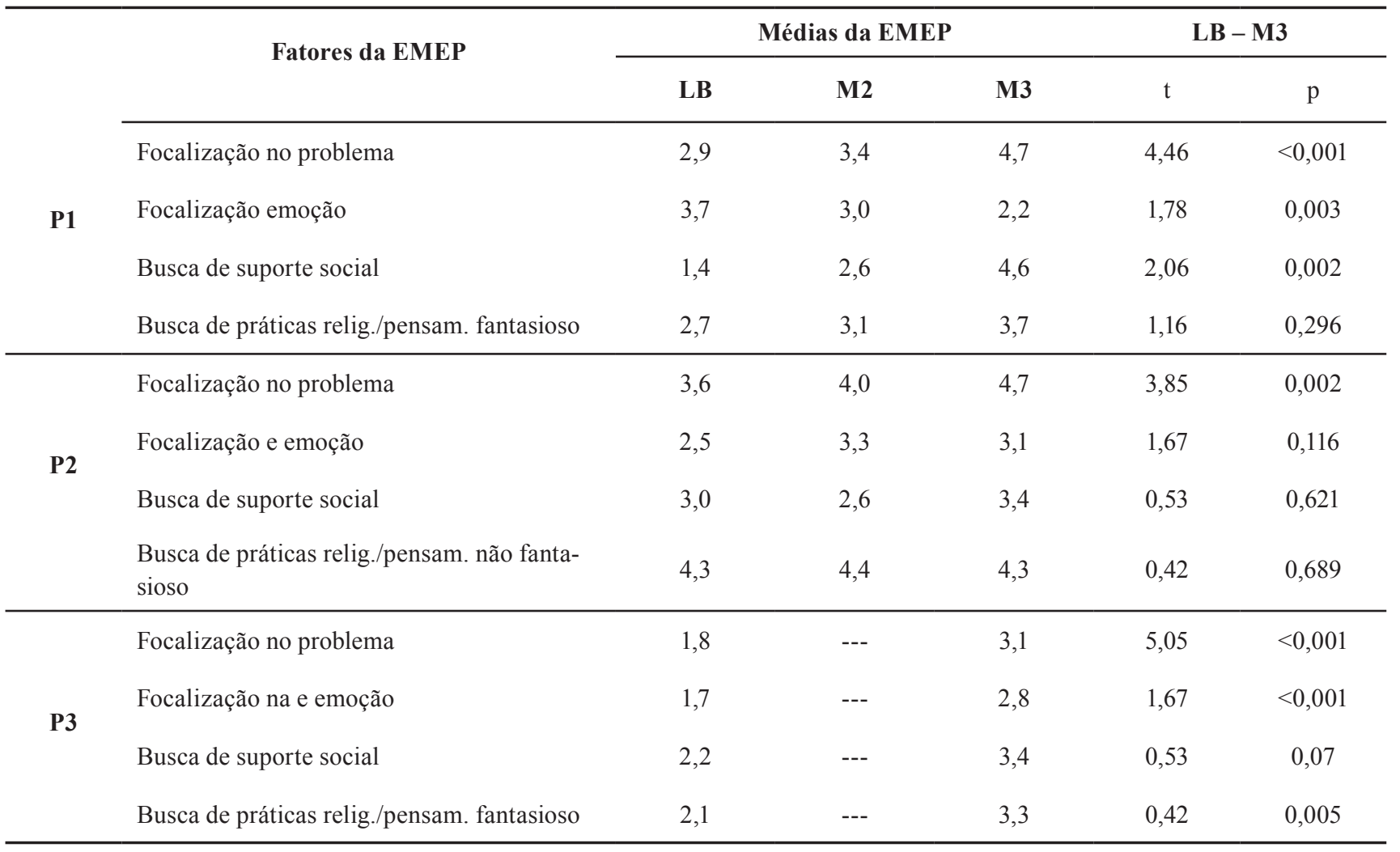

que seus escores são menores dos que os encontrados por P1 e P2 e ficam compreendidos no limite de um desvio-padrão da amostra de validação para todas as modalidades de enfrentamento, o que poderia implicar em indicação de avaliação complementar por parte da equipe de saúde e, provavelmente, na necessidade de intervenção psicológica.

\section{Contagens de linfócitos T CD4 e carga viral}

Para P1, pode-se perceber uma melhora nos seus indicadores entre os exames, que foram realizados justamente antes da LB e no mês de encerramento dos encontros. No primeiro momento, $\mathrm{P} 1$ apresentou uma contagem de CD4 de $92 / \mathrm{mm}^{3}$ e de carga viral de $16.049 / \mathrm{ml}$. Na segunda amostra, apresentou contagens de CD4 de $177 / \mathrm{mm}^{3}$ e carga viral de 250 cópias/ml, com aumento do CD4 e redução da carga viral, resultados que indicam adesão à TARV.

$\mathrm{O}$ participante P2 apresentou contagens baixíssimas

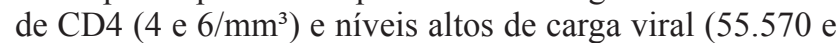
76.670 cópias $/ \mathrm{ml}$ ). Constatou-se que não houve mudanças relevantes de P2 quanto aos indicadores biológicos, sugerindo duas possibilidades: não adesão à TARV e/ou ineficácia terapêutica.

Para P3, observou-se uma piora no seu quadro imunológico e virológico, representando uma condição de grande vulnerabilidade para a ocorrência de infecções oportunistas. A primeira amostra apontava CD4 de $50 / \mathrm{mm}^{3}$ e carga viral de $3.073 / \mathrm{ml}$. Na segunda coleta, P2 apresentou CD4 de 19/ $\mathrm{mm}^{3}$ e carga viral de 22.842 cópias $/ \mathrm{ml}$.

\section{Discussão}

Os resultados sugerem que P1 e P2 chegaram ao final da atividade mais preparados para lidar com as dificuldades impostas pelo tratamento. Analisando os dados da EMEP, tanto P1 como P2 apresentaram resultados mais positivos ao final, o que pode indicar que a intervenção os ajudou a empregar estratégias de enfrentamento mais adaptativas frente à soropositividade, o que, segundo Chesney, Chambers, Taylor, Johnson e Folkman (2003), implica em estados psicológicos mais positivos.

É importante pontuar que o aumento dos escores da EMEP para P3, nos quatro fatores do instrumento, pode ser um alerta importante para pesquisadores e profissionais de saúde, como ilustração de que grande parte da aprendizagem acontece fora do espaço físico do serviço de saúde. Além disso, a baixa pontuação no fator focalização no problema, ao lado do escore relativamente alto em focalização na emoção, sugere que $\mathrm{P} 3$ poderia se beneficiar de uma intervenção psicológica regular, na medida em que apresentava dificuldades importantes de ajustamento à condição de soropositividade, o que poderia estar ocasionando as dificuldade de não adesão à TARV.

Observou-se que os melhores resultados foram os de $\mathrm{P} 1$, com maior coerência quanto às medidas psicológicas e biológicas, pois seus níveis de CD4 e CV apresentaram uma tendência de queda do indicador virológico e aumento do imunológico, acarretando a melhoria de sua condição de saúde. Havia, no entanto, a manutenção de relatos de 
desconforto e de dificuldades no uso da TARV, assim como indícios da presença de vulnerabilidades que poderiam levar a novas rupturas da adesão. Assim, parece que a intervenção fortaleceu a aquisição do repertório de adesão, reduziu percepções de barreiras e aumentou a percepção das vantagens do tratamento, minimizando vulnerabilidades.

O participante $\mathrm{P} 2$ apresentou nos dois momentos que se seguiram à intervenção-Momento 2 e Momento 3 - relatos de níveis satisfatórios de adesão. Apesar do quadro grave de imunodeficiência, não foi relatada a ocorrência de infecções oportunistas no período investigado. Ademais, com base nas informações fornecidas pelo participante, nos dados da LB e da intervenção, a conclusão era de que apresentava estado geral de saúde que podia ser avaliado como bom.

Alguns resultados ilustram, ainda, a mudança da percepção sobre o tratamento dos dois participantes da intervenção em comparação com P3. Constatou-se que P1 e P2, mesmo diante de relatos sobre algum nível de desconforto com a realização do tratamento, avaliaram que este era menos desagradável que no início da intervenção. Já com P3, houve a manutenção de uma relação conflituosa com a medicação e a clara percepção de seus efeitos como algo nocivo.

Outra mudança observada se referiu ao julgamento acerca do nível de dificuldade de realização da TARV. Os participantes P1 e P2 passaram de uma avaliação inicial de "muito difícil", para uma avaliação de que era "um pouco difícil". O participante P3 manteve sua apreciação que era "muito difícil" cumprir as prescrições. Esses exemplos falam a favor de um processo de resignificação do tratamento e de maior sentimento de autoeficácia, a partir de reestruturação cognitiva (Campos \& Thomason, 1998).

Em relação às expectativas de autoeficácia para realização da TARV, notou-se, em P1 e P2, uma mudança positiva, com o primeiro atingindo o escore máximo da escala no M3 $(4,0)$. No caso de P2, este apresentou níveis satisfatórios de percepção já no M2. Esses achados, somados aos encontrados na EMEP, indicam a eficácia de intervenções de base cognitivocomportamental em contextos de saúde-doença, permitindo uma avaliação positiva sobre sua utilização no atendimento de pessoas com dificuldades de adesão. Esses achados se somam aos resultados encontrados em outros estudos realizados com base nesse referencial teórico-metodológico (Folkman \& cols., 1986; Godin, Côté, Naccache, Lambert \& Trottier, 2005; Haidt \& Rodin, 1999).

\section{Considerações Finais}

Uma contribuição importante do estudo foi o desenvolvimento e planejamento de intervenção em grupo, de base cognitivo-comportamental, que lançou mão de técnicas de fácil aplicação, que podem ser usadas em contextos de atendimento individual e grupal. No entanto, antes da aplicação de técnicas que auxiliem no desenvolvimento de habilidades e no aprendizado de repertórios comportamentais, a consolidação do acolhimento e do vínculo é condição sine qua non para a boa relação profissional de saúde-usuário e, consequentemente, para a adesão ao tratamento. Entende-se ainda que seja essencial que iniciativas similares, de atendimento em grupo em serviços de saúde, sejam avaliadas, para acumular evidências empíricas sobre as vantagens e benefícios de tais práticas, conforme diversos autores têm demonstrado (Murphy \& cols., 2002; Wessler, 1996/1999).

Há necessidade, contudo, de parcimônia nas conclusões do estudo, especialmente pelo fato de a amostra ter sido de conveniência, levando à intervenção com dois participantes que já apresentavam algum interesse pela mudança comportamental. Assim, P3 claramente necessitava de um tipo similar de acompanhamento, por apresentar dificuldades evidentes para colocar em prática seus objetivos e estratégias terapêuticas. O reduzido número de pacientes participantes do estudo, além de realçar a necessidade de tal parcimônia, também traz um reforço pela busca da compreensão de tais fenômenos e pela elaboração de estratégias que procurem ajudar pessoas em tratamento a alcançar a adesão necessária para o restabelecimento da saúde.

\section{Referências}

Antoniazzi, A. S., Dell'Aglio, D. D., \& Bandeira, D. R. (1998). O conceito de coping: uma revisão teórica. Estudos de Psicologia, 3, 273-294.

Aspeling H. E., \& van Wyk, N. C. (2008). Factors associated with adherence to antiretroviral therapy for the treatment of HIVinfected women attending an urban care facility. International Journal of Nursing Practice, 14, 3-10.

Bandura, A. (1994a). Self-efficacy. Em V. S. Ramachaudran (Org.), Encyclopedia of human behavior. New York: Academic Press.

Bandura, A. (1994b). Social cognitive theory and exercise of control over HIV infection. Em R. J. DiClemente \& J. L. Peterson (Eds.), Preventing AIDS: Theories and methods of behavioral interventions (pp. 25-59). New York: Plenum.

Barros, T. M. (2003). Psicologia e saúde: intervenção em hospital geral. Em R. M. Caminha, R. Wainer, M. Oliveira \& N. M. Piccoloto (Orgs.), Psicoterapias cognitivo-comportamentais (pp. 239-246). São Paulo: Casa do Psicólogo.

Caballo, V.E., \& Buela-Casal, G. (1999). Técnicas diversas em terapia comportamental. Em V. E. Caballo (Org.), Manual de técnicas de terapia e modificação do comportamento (pp. 685-718) (M. D. Claudino, Trad.). São Paulo: Santos Livraria. (Trabalho original publicado em 1996)

Cade, N. V. (2001). Terapia de grupo para pacientes com hipertensão arterial. Revista de Psiquiatria Clínica, 28, 300304.

Campos, P. E., \& Thomason, B. (1998). Intervenciones cognitivo-conductuales en personas con VIH/SIDA. Em V. C. Caballo (Org.), Manual para el tratamiento cognitivo-conductual de los transtornos psicológicos, Vol 2 (pp. 453-473). Madri: Siglo Veintiuno.

Chesney, M. A., Chambers, D. B., Taylor, J. M., Johnson, L., M., \& Folkman, S. (2003). Coping effectiveness training for men living with HIV: Results from a randomized clinical trial testing a group-based intervention. Psychosomatic Medicine, 65, $1038-1046$. 
Dancey, P. C. A., \& Reidy, J. (2006). Estatística sem matemática para psicologia. Porto Alegre: Artmed.

Endler, N. S., Parker, J. D. A., \& Summerfeldt, L. J. (1998). Coping with health problems: Developing a reliable and valid multidimensional measure. Psychological Assessment, 10, 195-205.

Feilstrecker, N., Hatzenberger, R., \& Caminha, R. M. (2003). Técnicas cognitivo-comportamentais. Em R. M. Caminha, R. Wainer, M. Oliveira \& N. M. Piccoloto (Orgs.), Psicoterapias cognitivo-comportamentais (pp. 53-60). São Paulo: Casa do Psicólogo.

Folkman, S. Lazarus, R. S., Gruen, R. J., \& DeLongis, A. (1986). Appraisal, coping, health status, and psychological symptoms. Journal of Personality and Social Psychology, 50, 571-579.

Gebo, K. A., Keruly, J., \& Moore, R. D. (2003). Association of social stress, illicit drug use, and health beliefs with nonadherence to antiretroviral therapy. Journal of General Internal Medicine, $18,104-111$.

Godin, G., Côté, J., Naccache, H., Lambert, L., D., \& Trottier, S. (2005). Prediction of adherence to antiretroviral therapy: A oneyear longitudinal study. Aids Care, 17, 493 - 504.

Haidt, J., \& Rodin, J. (1999). Control and efficacy as interdisciplinary bridges. Review of General Psychology, 3, 317337.

Kelly, J. A., \& Kalichman, S. C. (2002). Behavioral research in HIV/Aids primary and secondary prevention: Recent advances and future directions. Journal of Consulting and Clinical Psychology, 70, 626-639.

Leite, J. C. C., Drachler, M. L., Centeno, M. O., Pinheiro, C. A. T., \& Amato, V. L (2002). Desenvolvimento de uma escala de auto-eficácia para adesão ao tratamento anti-retroviral. Psicologia Reflexão e Critica, 15, 121-133.

Lipp, M. E. N. (1997). Relaxamento para todos: controle o seu stress. Campinas: Papirus.

Ministério da Saúde (2007). Recomendações para terapia antiretroviral em adultos e adolescentes infectados pelo HIV. Brasília: Secretária de Vigilância em Saúde. Programa Nacional de DST e AIDS. Ministério da Saúde.

Ministério da Saúde (2008). Manual de adesão ao tratamento para pessoas vivendo com HIV e Aids. Brasília: Programa Nacional de DST e Aids/Ministério da Saúde.

Molassiotis, A., Morris, K., \& Trueman, I. (2007). The importance of the patient-clinician relationship in adherence to antiretroviral medication. International Journal of Nursing Practice, 13, 370-376.

Murphy, D. A., Lu, M. C., Martin, D. Hoffman, D., \& Marelich, W. D. (2002). Results of a pilot intervention trial to improve antiretroviral adherence among HIV-Positive patients. Journal of the Association of Nurses in AIDS Care, 13, 57-69.

Nezu, M., \& Nezu, C.M. (199). Treinamento em solução de problemas. Em V. E. Caballo (Org.), Manual de técnicas de terapia e modificação do comportamento (pp. 471-493) (M. D. Claudino, Trad.). São Paulo: Santos Livraria. (Trabalho original publicado em 1996)
Rehm, L. P. (1999). Métodos de autocontrole. Em V. E. Caballo (Org.), Manual de técnicas de terapia e modificação do comportamento (p. 581-605) (M. D. Claudino, Trad.). São Paulo: Santos Livraria. (Trabalho original publicado em 1996)

Reynolds, N. R., Testa, M. A., Marc, L. G., Chesney, M. A., Neidig, J. L., Smith, S. R., Vella, S., \& Robbins, G. K. (2004). Factors influencing medication adherence beliefs and self-efficacy in persons naive to antiretroviral therapy: A multicenter, crosssectional study. AIDS and Behavior, 8, 141-150.

Russel, C. K., Bunting, S. M., Graney, M., Hartig, M. T., Kisner, P., \& Brown, B. (2003). Factors that influence the medication decision making of persons with HIV/Aids: A taxonomic exploration. Journal of the Association of Nurses in AIDS Care, 14, 46-60.

Seidl, E .M. F, Melchíades, A., Caetano, T., Farias, V., \& Brito, A. (2007). Pessoas vivendo com HIV/Aids: variáveis associadas à adesão ao tratamento anti-retroviral. Cadernos de Saúde Pública, 23, 2305-2316.

Seidl, E. M. F., Tróccoli, B. T., \& Zannon, C. M. L. C. (2001). Análise fatorial de uma medida de estratégias de enfrentamento. Psicologia Teoria e Pesquisa, 17, 225-234.

Silva, A. M. M. (2004). Teoria da auto-eficácia. Em M. F. Dela Coleta (Org.), Modelos para pesquisa e modificação de comportamentos de saúde (pp. 131-168). Taubaté: Cabral.

Sun, H., Zhang, J., \& Fu, X. (2007). Psychological status, coping, and social support of people living with HIV/AIDS in Central China. Public Health Nursing, 24, 132-140.

Tuldrà, A., \& Wu, A. W. (2002). Interventions to improve adherence to antiretroviral therapy. Journal of Acquired Immune Deficiency Syndromes, Supplement 3, S154-S157.

Vera, M. N., \& Vila, J. (1999). Técnicas de relaxamento. Em V. E. Caballo (Org.), Manual de técnicas de terapia e modificação do comportamento (pp. 147-165) (M. D. Claudino, Trad.). São Paulo: Santos Livraria. (Trabalho original publicado em 1996)

Wessler, R. L. (1999). Terapia de grupo cognitivocomportamental. Em V. E Caballo (Org.), Manual de técnicas de terapia e modificação do comportamento (pp. 721-739) (M. D. Claudino, Trad.). São Paulo: Santos Livraria. (Trabalho original publicado em 1996)

White, J. R., \& Freeman, A. S. (2003). Terapia cognitivocomportamental em grupo para populações e problemas específicos (M. G. Armando, Trad.). São Paulo: Roca. (Trabalho original publicado em 2000) 